
\title{
25 Research Soure \\ The Therapeutic Effects of Human Embryonic Stem Cells-derived Immunity-and-matrix Regulatory Cells on Membranous Nephropathy
}

Huisong Zhou ( $\square$ liuyang@swufe.edu.cn )

Peking University https://orcid.org/0000-0001-7436-3013

Zhao Cui

Peking University First Hospital

Hui Wang

Peking University First Hospital

Ting-ting Gao

Chinese Academy of Sciences

Liu Wang

Chinese Academy of Sciences

Jun Wu

Chinese Academy of Sciences

\section{Zu-ying Xiong}

Peking University Shenzhen Hospital

Jie Hao

Chinese Academy of Sciences

Ming-hui Zhao

Peking University First Hospital

\section{Research Article}

Keywords: membranous nephropathy, immunity-and-matrix regulatory cells, treatment, regulatory $\mathrm{T}$ cells, $\mathrm{IL}-10$

Posted Date: January 28th, 2022

DOI: https://doi.org/10.21203/rs.3.rs-1262603/v1

License: (c) (1) This work is licensed under a Creative Commons Attribution 4.0 International License.

Read Full License 


\section{Abstract}

Background Primary membranous nephropathy $(\mathrm{MN})$ is a kidney-specific autoimmune disease. Human embryonic stem cells-derived immunity-and-matrix regulatory cells (hESC-IMRCs) have immunoregulatory functions. We hypothesized that hESC-IMRCs might have therapeutic effects on MN and be a potential treatment in clinical practice.

Methods Rats of Heymann nephritis were set up by immunization with sheep anti-rat Fx1A serum. hESCIMRCs were intravenously administrated upon the detection of proteinuria, with $6 \times 10^{6}$ cells (high-dose) or $3 \times 10^{6}$ cells (low-dose) in $1 \mathrm{ml}$ every other day. Splenocytes and IMRCs were co-cultured at different times and ratios. Cell types and cytokines were detected by flow cytometry and enzyme-linked immunosorbent assay.

Results Proteinuria of rats with Heymann nephritis was reduced remarkably to a level comparable to negative controls, in both low-dose (45.6 vs. $282.3 \mathrm{mg} / \mathrm{d}, \mathrm{P}<0.001)$ and high-dose (35.2 vs. $282.3 \mathrm{mg} / \mathrm{d}$, $\mathrm{P}<0.001) \mathrm{hESC}-\mathrm{IMRC}$ treatment groups. IgG and C3 deposit, glomerular basement membrane thickness (613.6 vs. $1014.3 \mathrm{~nm}, \mathrm{P}=0.003$ ) and foot process effacement ( 271.0 vs. $496.4 \mathrm{~nm}, \mathrm{P}<0.001$ ) was alleviated in the kidneys. The proportions of $C D 4+C D 25+T$ cells in circulation $(7.2 \mathrm{vs.} 3.4 \%, P=0.002)$ and in spleen ( 14.9 vs. $10.0 \%, P<0.001)$ were increased, the circulating level of IL-10 was increased (42.1 vs. $27.4 \mathrm{pg} / \mathrm{ml}, \mathrm{P}<0.001)$, and the circulating level of complement C3 was decreased (464.2 vs. $872.7 \mathrm{ng} / \mathrm{ml}$, $\mathrm{P}=0.010)$, after hESC-IMRC interventions. IL-10 increased remarkably in the co-culture supernatant of lymphocytes and IMRCs at 48 hours with ratio 10:1.

Conclusions The intravenously delivered hESC-IMRCs alleviated proteinuria and kidney injuries of Heymann nephritis, by their immunosuppressive functions through regulatory T cells and IL-10. These pre-clinical results indicate that IMRCs worth careful consideration for human trials in the treatment of $\mathrm{MN}$.

\section{Introduction}

Primary membranous nephropathy $(\mathrm{MN})$ is an autoimmune disease and a common cause of nephrotic syndrome in adults. It is characterized by the subepithelial formation of immune deposits containing antigens, IgG, and complement components [1,2]. The annual incidence of primary MN has been estimated as 1.2 per 100,000 adults in the United States and European countries [3], in contrast, a significant increase of patients with primary MN was witnessed in mainland China [4]. The main treatments of $\mathrm{MN}$ include supportive therapies using angiotensin-converting enzyme inhibitors or angiotensin II receptor blockers for lowering blood pressure and reducing urinary protein, and immunosuppressive therapies with or without steroids $[5,6]$. Even having received these treatments, some patients present with continuous nephrotic syndrome and kidney dysfunction $[5,6]$.

Stem cells are unspecialized cells with self-renewal and differentiation potentials. The therapy using stem cells is emerging to cure various inflammatory, degenerative and autoimmune diseases [7-10]. 
Mesenchymal stem cells (MSCs) present with an immune regulatory role in both adaptive and innate immune systems and have been widely used in clinical trials as immunosuppressive agents for autoimmune and inflammatory diseases, including graft-versus-host disease, multiple sclerosis, systemic lupus erythematosus, crescentic glomerulonephritis, acute kidney injury and chronic kidney disease [1117]. Human embryonic stem cells (hESCs)-derived MSC-like cell population, which is called immunity and matrix-regulatory cells (IMRCs) [18], has unique abilities in modulating immunity and regulating extracellular matrix production, compared to regular MSC populations. On the one hand, IMRCs resemble MSCs in their self-renewal and tri-lineage differentiation capacity. On the other hand, compared to primary umbilical cord mesenchymal stem cells, IMRCs display a higher consistency in quality and more potent immunomodulatory and anti-fibrotic functions.

In the present study, we administrated IMRCs treatments on Heymann nephritis, with the aim to explore the therapeutic effects and immune regulatory mechanism of MSCs on MN.

\section{Materials And Methods}

\section{Generation of hESC-IMRCs}

The hESC-IMRCs were generated by National Stem Cell Resource Center, Institute of Zoology, Chinese Academy of Sciences, Beijing, as described previously [18]. In brief, clinical hESCs were maintained in Essential $8^{\mathrm{TM}}$ basal medium (E8) on vitronectin-coated plates before dissociation into small clumps to form human embryoid bodies (hEBs) for 5 days. Subsequently, hEBs were transferred onto vitronectincoated plates and cultured for 14 additional days. The hEBs outgrowth cells were dissociated and passaged continuously in IMRCs Medium. After 5 passages, IMRCs were harvested for characterization. IMRCs possessed fibroblast-like morphology and maintained diploid karyotypes at passage 5. Copynumber variation analysis by whole-genome sequencing showed no chromosomal aneuploidies, large deletions nor duplication fragments. IMRCs showed an expression profile greatly differed from hESCs, and closely resembled primary umbilical cord-derived MSCs (UCMSCs). All pluripotency genes, mesendoderm genes, and ectoderm genes were extinguished. IMRCs expressed MSC-specific genes and surface markers, while negative of hematopoietic surface markers. IMRCs displayed the ability to undergo tri-lineage differentiation into mesenchymal tissues, such as adipocytes, chondroblasts and osteoblasts. The proliferation rate of IMRCs was higher than that of UCMSCs at passage 15. IMRCs were generally smaller than UCMSCs.

\section{Induction of passive Heymann nephritis}

Sprague-Dawley (SD) rats, male, with body weights of 100 to 120 grams, were immunized using sheep anti-rat Fx1A serum (Probetex, Inc., Texas, USA) $0.7 \mathrm{ml} / 100 \mathrm{~g}$ by a single intravenous injection. Twentyfour-hour urine and blood samples were collected before and after immunization at each week. All rats were sacrificed at the end of week 7 after immunization according to our previous experience. Kidney tissues, spleens and blood samples were collected at sacrifice. 


\section{Treatment with hESC-IMRCs}

Treatment was administrated upon the detection of proteinuria by urine dipsticks (Urit, Guilin, China) (approximately 3 weeks after immunization). The rats were randomly divided into three groups with the level of proteinuria comparable. For the high-dose treatment group $(n=10)$, hESC-IMRCs were injected into rats intravenously at $6 \times 10^{6}$ cells in $1 \mathrm{ml}$ every other day from week 3 to week 6 after immunization. For low-dose treatment group $(n=10)$, hESC-IMRCs were administrated at $3 \times 10^{6}$ cells in $1 \mathrm{ml}$ with the same method. Sterile physiological saline treatment was used on rats of disease controls $(n=10)$.

\section{Evaluation of disease severity}

The levels of urinary protein, serum creatinine, blood urea nitrogen, cholesterol, and triglyceride were analyzed by an automatic biochemical analyzer (UniCel DxC 600 Synchron; Beckman Coulter, Inc).

Kidney tissues were examined by light microscopy, immunofluorescence, and electron microscopy. For light microscopy, kidney tissues were fixed in $10 \%$ buffered formalin and embedded in paraffin. Kidney sections $(3 \mu \mathrm{m})$ were stained with hematoxylin and eosin, periodic acid-Schiff, periodic acid-sliver methenamine and Masson's trichrome. At least 60 glomeruli in each tissue were assessed. For immunofluorescence, cryosections $(5 \mu \mathrm{m})$ were fixed in acetone, blocked with $3 \%$ bovine serum albumin in PBS, and stained with fluorescein isothiocyanate (FITC)-conjugated goat anti-rat IgG (1:100,Jackson ImmunoResearch Laboratories Inc., Seattle, WA, USA) or FITC-conjugated goat anti-rat C3c (1:50,Abcam, Cambridge, UK). For electron microscopy, kidney tissues were immersed in cold $5 \%$ glutaraldehyde, postfixed in osmium tetroxide, and embedded in Epon 812. Sections were stained with uranyl acetate and lead citrate and examined on an electron microscope (JEM-1230; Jeol, Tokyo, Japan).

For evaluation of foot process width per length of GBM, two glomeruli were randomly selected from each kidney sample. A total of 20-25 representative non-overlapping digital micrographs were taken from each glomerulus under $\times 10,000$ magnification. The number of foot processes per micrometer of GBM and GBM thickness were calculated using Photoshop or ImageJ. The arithmetic mean of foot process width

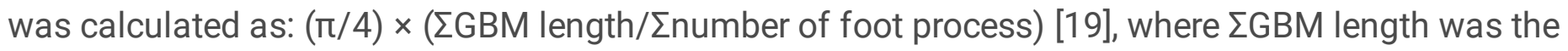
total GBM length measured in one glomerulus and $\Sigma$ number of foot process was the total number of one glomerulus foot process counted. The correction factor $(\pi / 4)$ had been applied to correct the random orientation when the foot processes were sectioned.

\section{Flow cytometric analysis}

The spleens were aseptically removed and disrupted by mechanical dissociation. After filtration through a 100- $\mu \mathrm{m}$ nylon screen, splenocytes were collected, washed, and suspended with red blood cell lysing buffer. The splenocytes were suspended in dilutedstaining perm wash buffer (BioLegend, San Diego, CA) at a concentration of $1 \times 10^{7}$ cells $/ \mathrm{ml}$. Cell suspensions or blood samples $100 \mu \mathrm{l}$ were stained with FITCanti-CD3 (1:500, BioLegend, San Diego, CA, USA), APC-anti-CD4 (1:100, BioLegend), PerCP-anti-CD8a (1:100, BioLegend), PE-anti-CD25 (1:100, BioLegend)and APC-Cy7 anti-CD45 (1:100, BioLegend)or 
isotype-matchedcontrols (1:200, BioLegend), according to the manufacturer's instructions. The samples were mixed gently, incubated for $20 \mathrm{~min}$ at $4^{\circ} \mathrm{C}$ in the darkness and subsequently analyzedusing FACS Verse flow (Becton Dickinson, CA, USA). The gating strategies are shown in supplementalFigure.

\section{Co-culture and measurement of cytokine production}

The splenocytes were centrifuged at $1500 \mathrm{rpm}$ for $3 \mathrm{~min}$ and resuspended with IMRC culture medium (Chinese Academy of Sciences) at a density of $1 \times 10^{6} \mathrm{cells} / \mathrm{ml}$. Splenocytes cells and hESC-IMRCs were co-cultured at a ratio of 10:1 in 96-well culture plates. The cell concentration of hESC-IMRCs was ranged from $2 \times 10^{3}$ cells to $2 \times 10^{5}$ cells. The culture supernatants were collected at $24 \mathrm{~h}, 48 \mathrm{~h}$ and $72 \mathrm{~h}$ and stored at $-80^{\circ} \mathrm{C}$ until assayed for IFN- $\gamma$, IL-2 and IL-10, by commercial enzyme-linked immunosorbent assay kits (Biotech Co., Beijing, China), according to the manufacturer's instructions.

The plasma levels of IL-10 and complement C3 were measured by commercial enzyme linked immunosorbent assay kits (ab157731, Abcam, Cambridge, UK), according to the manufacturer's protocols.

\section{Statistical Analyses}

SPSS version 22.0 (SPSS Inc., Chicago, IL, USA) was used for statistical analysis. Results were expressed as mean \pm SD. Differences in quantitative parameters were assessed using separate individual t-test for data that were normally distributed or Mann-Whitney $U$ test for data that were not normally distributed. $\mathrm{P}$ values $₫ 0.05$ were considered statistically significant.

\section{Study Approval}

All animal experiments were approved by the Experimental Animal Ethics Committee of Peking University First Hospital, Beijing, China.

\section{Results}

\section{Effect of hESC-IMRCs on proteinuria of Heymann nephritis}

The rats developed heavy proteinuria in the third week after the passive immunization of anti-rat $\mathrm{Fx} 1 \mathrm{~A}$ serum, with urinary protein much higher than negative controls $(404.4 \pm 23.8$ vs. $17.6 \pm 2.4 \mathrm{mg} / \mathrm{d}$, $\mathrm{P}<0.001$, Figure 1).Then IMRCtreatment was administrated upon the detection of proteinuria, approximately 3 weeks after immunization.

In the high-dose treatment group $(\mathrm{n}=10)$, hESC-IMRCs were intravenously administrated every other day with $6 \times 10^{6}$ cells in $1 \mathrm{ml}$ from week 3 to week 6 . After treatment, urinary protein was signi $\square$ cantly reduced at week 4 (219.1 \pm 50.6 vs. $352.5 \pm 40.5 \mathrm{mg} / \mathrm{d}, P=0.049)$, week 5 ( $50.3 \pm 6.5$ vs. $330.0 \pm 53.3 \mathrm{mg} / \mathrm{d}$, $\mathrm{P}=0.001)$, week $6(42.1 \pm 5.5$ vs. $281.5 \pm 51.8 \mathrm{mg} / \mathrm{d}, \mathrm{P}<0.001)$, and week 7 (35.2 \pm 7.2 vs. $282.3 \pm 51.8$ $\mathrm{mg} / \mathrm{d}, \mathrm{P}<0.001)$, compared to those in disease control group with sterile physiological saline treatment $(n=10)$ (Figure 1). 
In the low-dose treatment group $(n=10)$, hESC-IMRCs were administrated at $3 \times 10^{6}$ cells in $1 \mathrm{ml}$ with the same method. After treatment, urinary protein was signi $\square$ cantly reduced at week 4 (188.3 \pm 20.1 vs. 352.5 $\pm 40.5 \mathrm{mg} / \mathrm{d}, \mathrm{P}=0.008)$, week 5 (42.5 \pm 6.2 vs. $330.0 \pm 53.3 \mathrm{mg} / \mathrm{d}, \mathrm{P}<0.001)$, week 6 (62.4 $\pm 10.1 \mathrm{vs.} 281.5$ $\pm 51.8 \mathrm{mg} / \mathrm{d}, \mathrm{P}=0.001)$, and week 7 (45.6 \pm 7.4 vs. $282.3 \pm 51.8 \mathrm{mg} / \mathrm{d}, P<0.001)$, compared to those in disease controls(Figure 1). There was no difference in proteinuria between the two groups of different IMRC doses $(P>0.05)$.

\section{Effect of hESC-IMRCs on kidney pathologic injuries of Heymann nephritis}

In the disease control group,diffuse granular staining of IgG and C3was shown along the glomerular capillary walls. Their intensities were weaker in both high-dose and low-dose IMRC treatment groups at week 7 (Figure 2).

In the disease control group, electron microscopy showed diffusive and extensive podocyte foot processes effusion, electron-dense deposits under epithelial cells and glomerular basement membranes diffuse thickening. These kidney injuries were alleviated in IMRC treatment groups of both doses (Figure 2). Quantitative analysis of foot process width showed that compared to disease controls, the foot process width in high-dose IMRCgroup (624.0 \pm 103.1 vs. $1014.3 \pm 152.6 \mathrm{~nm}, \mathrm{P}=0.005)$ and that in lowdose IMRC group (613.6 \pm 53.1 vs. $1014.3 \pm 152.6 \mathrm{~nm}, \mathrm{P}=0.003$ ) were significantly decreased at week 7 (Figure 3). Quantitative analysis of glomerular basement membrane thickness showed that compared to the disease controls, the basement membrane thickness in high-dose IMRC group (304.4 \pm 18.0 vs.496.4 \pm $32.2 \mathrm{~nm}, \mathrm{P}<0.001)$ and that in low-dose IMRC group ( $271.0 \pm 30.0$ vs. $496.4 \pm 32.2 \mathrm{~nm}, \mathrm{P}<0.001)$ was significantly decreased at week 7 (Figure 3).

\section{The immune regulation effects of hESC-IMRCs in vivo}

We assessed the level of circulating IL-10 in the disease control group, which was comparable to that of negative controls at week 7 ( $27.4 \pm 5.4$ vs. $23.4 \pm 3.6 \mathrm{pg} / \mathrm{ml}, \mathrm{P}=0.063)$ (Figure 4). However, circulating IL10 was increased in both high-dose IMRC group ( $41.9 \pm 7.1$ vs. $27.4 \pm 5.4 \mathrm{pg} / \mathrm{ml}, \mathrm{P}<0.001)$ and low-dose IMRC group (42.1 \pm 5.5 vs. $27.4 \pm 5.4 \mathrm{pg} / \mathrm{ml}, \mathrm{P}<0.001)$, compared to disease controls at week 7 .

The proportion of $\mathrm{CD} 4^{+} \mathrm{CD} 25^{+} \mathrm{T}$ cells in $\mathrm{CD} 4^{+} \mathrm{T}$ lymphocyte cells was higher in circulation of the two IMRC-treated groups (high-dose: $7.4 \pm 3.3$ vs. $3.4 \pm 1.3 \%, P=0.002$; low-dose: $7.2 \pm 3.1$ vs. $3.4 \pm 1.3 \%$, $\mathrm{P}=0.002)$, compared to that of disease control group. The proportion of $\mathrm{CD} 4^{+} \mathrm{CD} 25^{+} \mathrm{T}$ cells was also higher in spleen of the two IMRC-treated groups (high-dose: $15.5 \pm 2.0$ vs. $10.0 \pm 1.3 \%, P<0.001$; low-dose: $14.9 \pm 1.8$ vs. $10.0 \pm 1.3 \%, P<0.001$ ), compared to that of disease control group (Figure 4).

The plasma level of C3 was significantly increased in disease controls (Figure 5). After IMRCtreatments, it was decreased in both high-dose group ( $498.6 \pm 157.9$ vs. $872.7 \pm 126.5 \mathrm{ng} / \mathrm{ml}, \mathrm{P}=0.016)$ and low-dose group ( $464.2 \pm 50.0$ vs. $872.7 \pm 126.5 \mathrm{ng} / \mathrm{ml}, \mathrm{P}=0.010$ ), compared to that of disease controls at week 7 
(Figure 5). There was no difference in plasma level of C3 between the two groups of different IMRC doses $(P>0.05)$.

\section{The immune regulation effect of hESC-IMRCs in vitro}

hESC-IMRCs were co-cultured with the splenic lymphocytes from Heymann nephritis rats at a density ratio of 10:1 (lymphocytes: MSCs) (Figure 6). IL-10 expression in the supernatant was analyzed at different time points. After $24 \mathrm{~h}$ of co-culture, it was $74.1 \pm 1.3 \mathrm{pg} / \mathrm{ml}$ in the co-culture supernatant, much higher than that in the supernatant of splenic lymphocytes from disease rats without IMRC co-culture $(29.2 \pm 2.1 \mathrm{pg} / \mathrm{ml}, \mathrm{P}=0.004$, Figure 1), splenic lymphocytes from negative control rats with IMRC coculture $(29.0 \pm 2.2 \mathrm{pg} / \mathrm{ml}, \mathrm{P}=0.004)$, and splenic lymphocytes from negative control rats without IMRC coculture $(29.2 \pm 3.3 \mathrm{pg} / \mathrm{ml}, \mathrm{P}=0.004)$. After $48 \mathrm{~h}$, the level of IL-10 was $76.3 \pm 6.5 \mathrm{pg} / \mathrm{ml}$ in the supernatant of splenic lymphocytes from disease rats with IMRC co-culture, which was significantly higher than that of splenic lymphocytes from disease rats without IMRC co-culture $(28.5 \pm 2.3 \mathrm{pg} / \mathrm{ml}, \mathrm{P}=0.004)$, splenic lymphocytes from negative control rats with IMRC co-culture $(29.8 \pm 2.0 \mathrm{pg} / \mathrm{ml}, \mathrm{P}=0.004)$, and splenic lymphocytes from negative control rats without IMRC co-culture $(27.3 \pm 3.1 \mathrm{pg} / \mathrm{ml}, \mathrm{P}=0.004)$. After $72 \mathrm{~h}$, IL-10 was $46.0 \pm 4.0 \mathrm{pg} / \mathrm{ml}$ in the supernatant of splenic lymphocytes from disease rats with IMRC coculture, which was still higher than the other three groups $(P<0.01)$.

IL-10 expression was analyzed with different cell numbers of hECS-IMRCs at 48 hours. When the ratio of splenocytes to IMRCs was 10:1 $\left(2 \times 10^{5}: 2 \times 10^{4}\right)$, IL-10 expression was $76.3 \pm 6.5 \mathrm{pg} / \mathrm{ml}$ in the co-culture supernatant, which was higher than that in the supernatant with splenocytes and IMRC co-culture at 1:1 $\left(2 \times 10^{5}: 2 \times 10^{5}\right)(62.4 \pm 3.7 \mathrm{pg} / \mathrm{ml}, \mathrm{P}=0.001)$, and that in splenocytes and IMRC co-culture at $100: 1$ $\left(2 \times 10^{5}: 2 \times 10^{3}\right)(24.8 \pm 5.8 \mathrm{pg} / \mathrm{ml}, \mathrm{P}<0.001)$ (Figure 6).

\section{Discussion}

To our knowledge, this is the first study that MSCs were administrated on Heymann nephritis rats for the treatment of $\mathrm{MN}$. We found that proteinuria was reduced remarkably to a level comparable to negative controls, in both low-dose and high-dose treatment groups. IgG and C3 deposit, glomerular basement membrane thickness and foot process effacement werealleviated in the kidneys. This efficacy was noted when IMRC treatment was administrated at week 3 after the rats presented with proteinuria. All these results demonstrate that IMRCs might have potential clinical values for the treatments of MN patients.

Clinical studies with primary MSCs derived from the umbilical cord, bone marrow or adipose tissue have been hampered by the lack of available donors, limited cell numbers from each donor, donor and tissue heterogeneity, inconsistent cell quality and the lack of standardized cell preparations. Moreover, primary MSCs show limited self-renewal capacities and finite lifespans. In the current study, we used IMRCs derived from self-renewing hESC cultures with serum-free reagents, which have unique merits to solve these problems [18]. IMRCs, while similar to primary UCMSCs, were superior in their long-term proliferative capacity, hyper-immunomodulatory and anti-fibrotic functions. The cell diameters of IMRCs were generally smaller than UCMSCs, suggesting that they pose lower risks for pulmonary embolism after 
injection. IMRCs did not engraft, nor transdifferentiate or initiate tumorigenesis, showing excellent potential for short- and long-term safety profiles by a range of in vitro and in vivo assays [20-23].

Primary $\mathrm{MN}$ is a kidney-specific autoimmune disease mediated by autoantibodies towards antigens on podocytes and the subsequent podocyte injuries resulting from complement activation [24]. After IMRC treatments, we found that the elevated level of $\mathrm{C} 3$ in the circulation of the rats with Heymann nephritis was significantly decreased. At the same time, the glomerular deposition of $\mathrm{C} 3$ and the resultant thickening of basement membrane and podocyte foot processes fusionwere alleviated. These results provide evidence that IMRC treatment could inhibit the pathogenesis of MN and exert therapeutic effects. It is noted that the level of circulating $\mathrm{C} 3$ in rats of interventions was decreased to a similar level as that in negative controls, but not lower than that, which indicates that IMRC treatment does not lead to excessive consumption of complement, thus avoiding the side effects of increased infection risk associated with complement exhaustion therapies.

In the current study, we found that the proportions of $\mathrm{CD} 4^{+} \mathrm{CD} 25^{+} \mathrm{T}$ lymphocytes in all $\mathrm{CD} 4^{+} \mathrm{T}$ cells were significantly increased in the detection of spleen and circulating $T$ cell subsets after both doses of hESCIMRC treatments. $\mathrm{CD} 4^{+} \mathrm{CD} 25^{+} \mathrm{T}$ lymphocytes are the main cells in the regulatory $\mathrm{T}$ cells family. Its main functions include inhibiting autoimmune response, preventing injurious immunopathology, and maintaining immune balance $[25,26]$. This finding suggested that IMRC infusion may play a therapeutic role by up-regulating or activating regulatory $T$ cell subsets. It has been shown that MSCs can generate T regulatory cells in vitro, from activated human peripheral blood mononuclear cells, mouse splenocytes or isolated $\mathrm{CD} 4^{+} \mathrm{T}$ cells $[27,28]$. Our experiments in vivo imply that this mechanism may also lead to a therapeutic effect of IMRCs in MN patients.

IL-10 plays an immunosuppressive role in various types of cells. After IMRC treatments, the circulating IL10 level of rats with Heymann nephritis was significantly increased compared to those of disease controls and negative controls. At the same time, no difference was shown on IL-2 or INF-y (data not shown). It suggests that IMRCs may exert the immunosuppressive effect on $\mathrm{MN}$ by promoting a shift of $\mathrm{T}$ lymphocytes immune balance from Th1 to Th2, thereby reducing kidney injuries. This finding is consistent with the elevation of regulatory T cells after MSCs treatments. Treg inhibits the proliferation of juvenile and memory $T$ cells mainly through the production of IL-10 [29].

The inhibitory effect of IMRCs on the proliferation of T lymphocytes is dose-dependent and timedependent. In our co-culture assay, we designed the ratio of IMRCs and T lymphocytes at 1:10 and found that IL-10 level was increased after 24 hours of co-culture, the highest at 48 hours and decreased at 72 hours. It may provide some references for the medication interval of IMRCs in potential clinical practice. Previous studies [30] have found that when the ratio of IMRCs to T lymphocytes is greater than 1:9, the inhibition effects occur. The inhibition effects disappear when the number of MSCs is less than $1 \%$ of T lymphocytes. Our results of the co-culture assay were consistent with that. We further assessed IL-10 level from the supernatant of IMRCs and lymphocytes with the ratio of 1:1, and found no increasement of IL-10 compared to that of IMRCs and lymphocytes 1:10. In the rats of Heymann nephritis, we also found 
similar therapeutic effects between two doses of IMRCs interventions. These results suggest to avoid an excessive amount of IMRCs in clinical usage for the lacking of further benefit but the risks of side effects.

In summary, our findings showed that intravenously delivered hESC-IMRCs significantly alleviated proteinuria and kidney injuries of Heymann nephritis in vivo. The mechanism may be mediated by the immunosuppressive effects of IMRCs through regulatory T cells upregulation and IL-10 production. These pre-clinical results indicate that IMRCs are worth careful consideration for human trials in the treatment of MN.

\section{Conclusions}

The intravenously delivered hESC-IMRCs alleviated proteinuria and kidney injuries of Heymann nephritis, by their immunosuppressive functions through regulatory $T$ cells and IL-10. These pre-clinical results indicate that IMRCs worth careful consideration for human trials in the treatment of MN.

\section{Abbreviations}

MN: Primary membranous nephropathy

hESC: Human embryonic stem cells

IMRCs: immunity-and-matrix regulatory cells

hESC-IMRCs: Human embryonic stem cells-derived immunity-and-matrix regulatory cells

IMRCs: immunity-and-matrix regulatory cells

IgG: immunoglobulin G

C3: complement component 3

CD4: cluster of differentiation 4

CD25: cluster of differentiation 25

IL-10: interlukin-10

MSCs: Mesenchymal stem cells

UCMSCs: umbilical cord-derived MSCs

Fx1A: Proximal tubular epithelial cell brush border extract

GBM: glomerular basement membrane 


\section{Declarations}

\section{Availability of data and materials}

The datasets used and/or analysed during the current study are available from the corresponding author on reasonable request.

\section{Acknowledgements}

The support by Jin-ying Wang is greatly appreciated.

\section{Funding}

This work is supported by grants of Natural Science Foundation of China $(81870486,82070732$, 82090021) and National Key Research and Development Program (2020YFA0804003).

\section{Contributions}

Hypothesis and experimental design: $\mathrm{ZC}, \mathrm{MHZ}, \mathrm{ZYX}, \mathrm{JH}$. Conduction of the animal experiment: HSZ,Conduction of the cells experiment TTG, LW, JW, Analysis and interpretation of pathological tissue: HW. Writing/Revision: All authors. All authors read and approved the final manuscript.

\section{Ethics declarations}

\section{Ethics approval and consent to participat}

The study protocol was reviewed by the Peking University First Hospital ethics committee (Document No. 201927). All cells and animals experimental designation were based on animal research, which ensured that the data from animal experiments could be fully evaluated and utilized.

\section{Consent for publication}

Written informed consent for publication was obtained from all participants

\section{Competing interests}

None of the authors have any competing interests.

\section{References}

1. Couser WG. Primary Membranous Nephropathy. Clin J Am Soc Nephrol. 2017 Jun 7;12(6):983-997. DOI: $10.2215 /$ CJN.11761116

2. Beck LH, Bonegio R, Lambeau G, et al. M-Type Phospholipase A2 Receptor as Target Antigen in Idiopathic Membranous Nephropathy. N Engl J Med. 2009 Jul 2;361(1):11-21. DOI: 
3. Floege J, Amann K. Primary glomerulonephritides. Lancet. 2016 May 14;387(10032):2036-48. doi: 10.1016/S0140-6736(16)00272-5.

4. Xu X, Wang G, Chen N, Lu T, Nie S, Xu G, Zhang P, Luo Y, Wang Y, Wang X, Schwartz J, Geng J, Hou FF. Long-Term Exposure to Air Pollution and Increased Risk of Membranous Nephropathy in China. J Am Soc Nephrol. 2016 Dec;27(12):3739-3746. doi: 10.1681/ASN.2016010093.

5. Kidney Disease: Improving Global Outcomes (KDIGO) Glomerular Diseases Work Group. KDIGO 2021 Clinical Practice Guideline for the Management of Glomerular Diseases. Kidney Int,2021,100(4S):S1S276.

6. Kidney Disease: Improving Global Outcomes (KDIGO) Glomerular Diseases Work Group. KDIGO Clinical Practice Guideline for Lipid Management in Chronic Kidney Disease. Kidney Int Suppl,2013,3(3):259-305.

7. NaikS, LarsenSB, CowleyCJ, Fuchs Two to Tango: Dialog between Immunity and Stem Cells in Health and Disease. Cell. 2018 Nov 1;175(4):908-920. doi: 10.1016/j.cell.2018.08.071.

8. Mirzaei H, Sahebkar A, Sichani LS, et al. Therapeutic application of multipotent stem cells. J Cell Physiol. 2018 Apr;233(4):2815-2823. doi: 10.1002/jcp.25990.

9. Cipriani P, Carubbi F, Liakouli V, et al. Stem cells in autoimmune diseases: Implications for pathogenesis and future trends in therapy. Autoimmun Rev. 2013 May;12(7):709-16. doi: 10.1016/j.autrev.2012.10.004.

10. Zakrzewski W, Dobrzyński M, Szymonowicz M, Rybak Z. Stem cells: past, present, and future. Stem Cell Res Ther. 2019 Feb 26;10(1):68. doi: 10.1186/s13287-019-1165-5.

11. Fujii S, Miura Y, Fujishiro A, et al. Graft-Versus-Host Disease Amelioration by Human Bone Marrow Mesenchymal Stromal/Stem Cell-Derived Extracellular Vesicles Is Associated with Peripheral Preservation of Naive T Cell Populations. Stem Cells. 2018 Mar;36(3):434-445. doi: $10.1002 /$ stem.2759.

12. XuJY, Chen JT, Li WL, et al. Additive Therapeutic Effects of Mesenchymal Stem Cells and IL-37 for Systemic Lupus Erythematosus. J Am Soc Nephrol. 2020 Jan;31(1):54-65. doi:

10.1681/ASN.2019050545.

13. FuruhashiK, TsuboiN, ShimizuA, et al. Serum-starved adipose-derived stromal cells ameliorate crescentic GN by promoting immunoregulatory macrophages. J Am Soc Nephrol. 2013 Mar;24(4):587-603. doi: 10.1681/ASN.2012030264.

14. Fazekas B, Griffin MD. Mesenchymal stromal cell-based therapies for acute kidney injury: progress in the last decade. Kidney Int. 2020 Jun;97(6):1130-1140. doi: 10.1016/j.kint.2019.12.019.

15. Sivanathan KN, Coates PT. Improving human kidney function in renovascular disease with mesenchymal stem cell therapy. Kidney Int. 2020 Apr;97(4):655-656. doi: 10.1016/j.kint.2019.12.020.

16. Perico N, Casiraghi F, Remuzzi G. Clinical Translation of Mesenchymal Stromal Cell Therapies in Nephrology. J Am Soc Nephrol. 2018 Feb;29(2):362-375. doi: 10.1681/ASN.2017070781.

17. Kuppe C, Kramann R. Role of mesenchymal stem cells in kidney injury and fibrosis. Curr Opin Nephrol Hypertens. 2016 Jul;25(4):372-7. doi: 10.1097/MNH.0000000000000230. 
18. Wu J, Song DY, Li ZW, et al. Immunity-and-matrix-regulatory cells derived from human embryonic stem cells safely and effectively treat mouse lung injury and fibrosis. Cell Res. 2020 Sep;30(9):794809. doi: 10.1038/s41422-020-0354-1.

19. White KE, Bilous RW. Estimation of podocyte number: a comparison of methods. Kidney Int. 2004 Aug;66(2):663-7. doi: 10.1111/j.1523-1755.2004.00787.x.

20. LiuJ, Hou ZR, Wu J, et al. Infusion of hESC derived Immunity-and-matrix regulatory cells improves cognitive ability in early-stage AD mice. Cell Prolif. 2021 Aug;54(8):e13085. doi: 10.1111/cpr.13085.

21. XingD, Wang K, Wu J, et al. Clinical-Grade Human Embryonic Stem Cell-Derived Mesenchymal Stromal Cells Ameliorate the Progression of Osteoarthritis in a Rat Model. Molecules. $2021 \mathrm{Jan}$ 24;26(3):604. doi: 10.3390/molecules26030604.

22. Yang S, Liu P, Jiang Y, et al. Therapeutic Applications of Mesenchymal Stem Cells in Idiopathic Pulmonary Fibrosis. Front Cell Dev Biol. 2021 Mar 9;9:639657. doi: 10.3389/fcell.2021.639657.

23. WuJ, Zhou X, Tan YQ, et al. Phase 1 trial for treatment of COVID-19 patients with pulmonary fibrosis using hESC-IMRCs. Cell Prolif. 2020 Dec;53(12):e12944. doi: 10.1111/cpr.12944.

24. Haddad G, Lorenzen JM, Ma H, et al. Altered glycosylation of IgG4 promotes lectin complement pathway activation in anti-PLA2R1-associated membranous nephropathy. JClin Invest. $2021 \mathrm{Mar}$ 1;131(5):e140453. doi: 10.1172/JCl140453.

25. Roemhild A, Otto NM, Moll G, et al. Regulatory T cells for minimising immune suppression in kidney transplantation: phase I/Ila clinical trial. 2020 Oct 21;371:m3734. doi: 10.1136/bmj.m3734.

26. Ooi JD, Petersen J, Tan YH, et al. Dominant protection from HLA-linked autoimmunity by antigenspecific regulatory T cells. Nature 2017; 545(7653): 243-247.

27. Luz-Crawford $P$, Kurte M, Bravo-Alegría J, et al. Mesenchymal stem cells generate a CD4+CD25+Foxp3+ regulatory T cell population during the differentiation process of Th1 and Th17 cells. Stem Cell Res Ther. 2013 Jun 4;4(3):65. doi: 10.1186/scrt216.

28. Fiori A, Uhlig S, Klüter H, Bieback K. Human Adipose Tissue-Derived Mesenchymal Stromal Cells Inhibit CD4+ T Cell Proliferation and Induce Regulatory T Cells as Well as CD127 Expression on CD4+CD25+ T Cells. 2021 Jan 1;10(1):58. doi: 10.3390/cells10010058.

29. Proto JD, Doran AC, Gusarova G, et al. Regulatory T Cells Promote Macrophage Efferocytosis during Inflammation Resolution. 2018 Oct 16;49(4):666-677.e6. doi: 10.1016/j.immuni.2018.07.015.

30. Blanc KL, Rasmusson I, Götherström C, et al. Mesenchymal stem cells inhibit the expression of CD25 (interleukin-2 receptor) and CD38 on phytohaemagglutinin-activated lymphocytes. Scand J Immunol. 2004 Sep;60(3):307-15. doi: 10.1111/j.0300-9475.2004.01483.x.

\section{Supplemental Figure}

Supplemental Figure is not available with this version.

\section{Figures}


a.

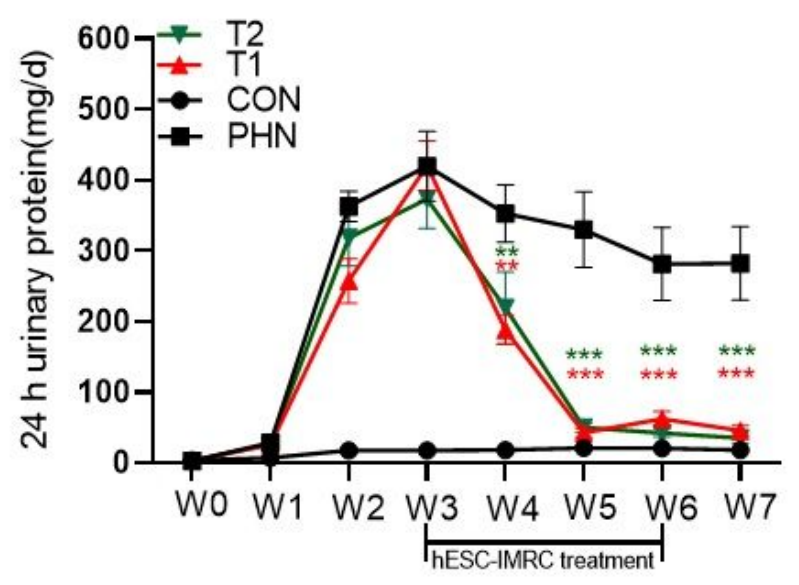

b.

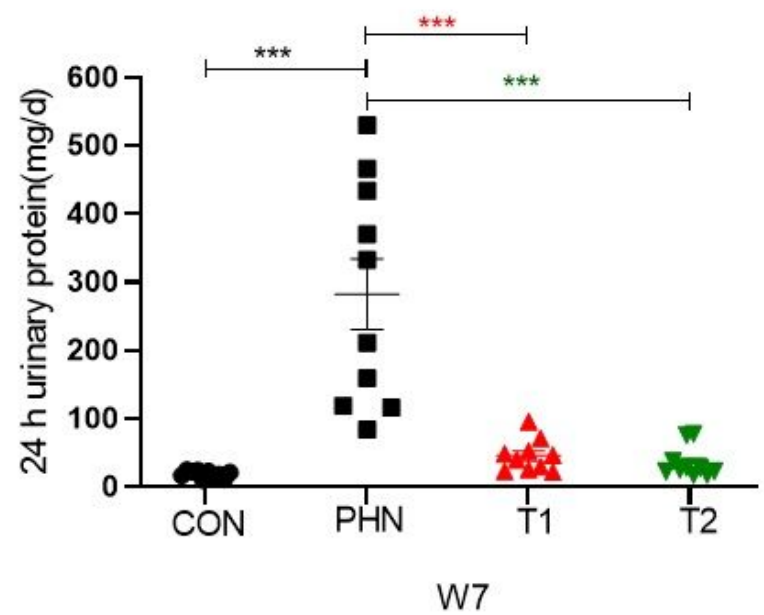

Figure 1

The clinical parameters of rats with passive Heymann nephritis and those after hESC-IMRC treatments.

The rats developed heavy proteinuria from week 3 after the passive immunization of anti-rat Fx1A serum (a). Then IMRCs were intravenously administrated every other day with $3 \times 10^{6}$ cells $(T 1, n=10)$ or $6 \times 10^{6}$ cells $(T 2, n=10)$ in $1 \mathrm{ml}$ from week 3 to week 6 . The urinary protein was significantly reduced in both groups, compared to that in disease controls $\left(^{*}\right)$ with sterile physiological saline treatment $(P H N, n=10)$, and was similar like that in negative controls $(C O N, n=10)$ at week $7(b) .{ }^{*} P<0.05,{ }^{* \star} P<0.01,{ }^{* \star * P} P<0.001$. 

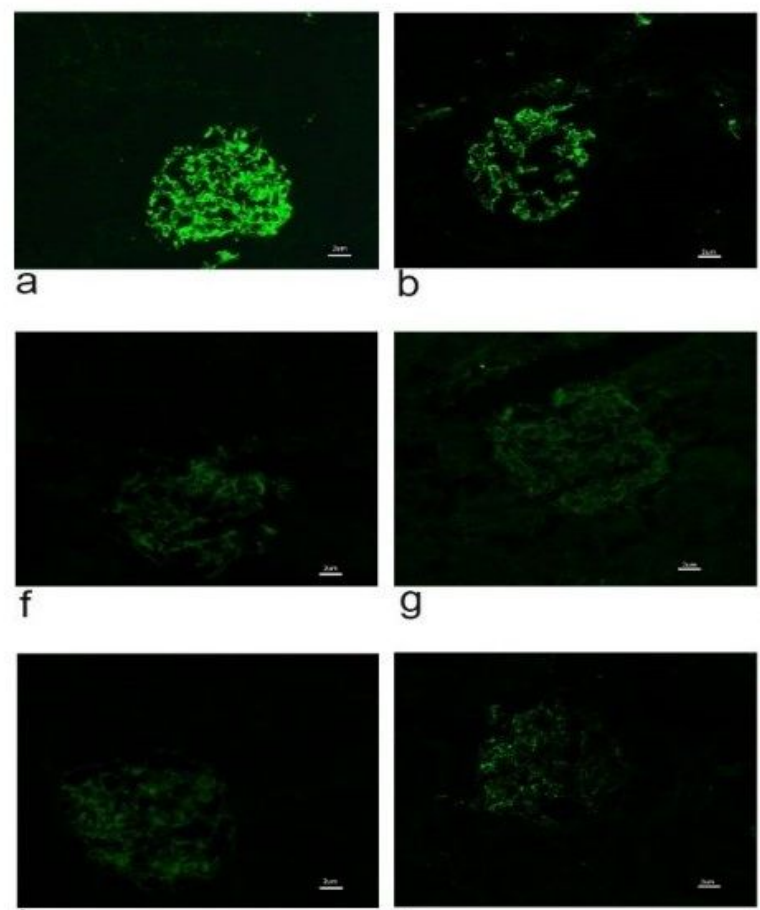

$\mathrm{k}$

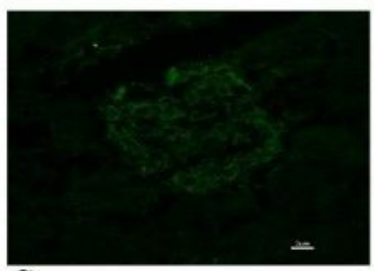

$\mathrm{g}$
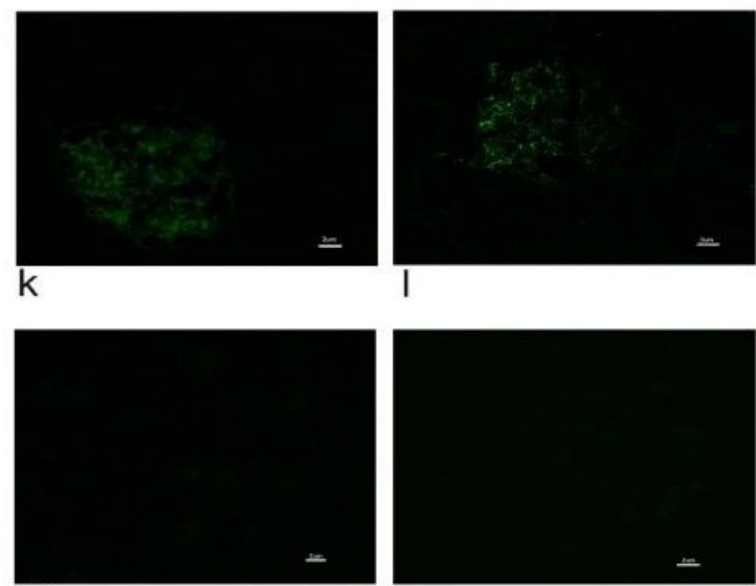

p

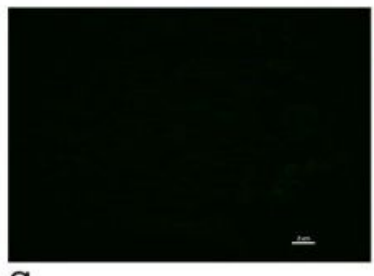

q
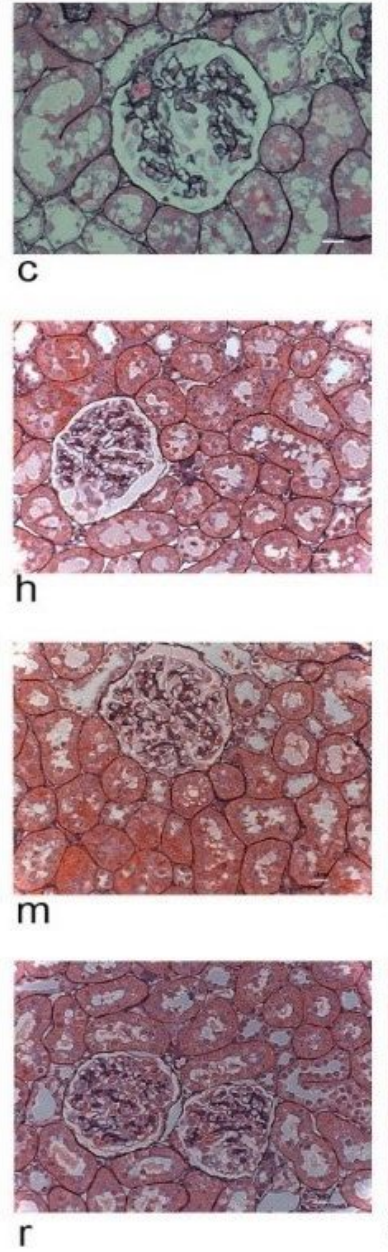
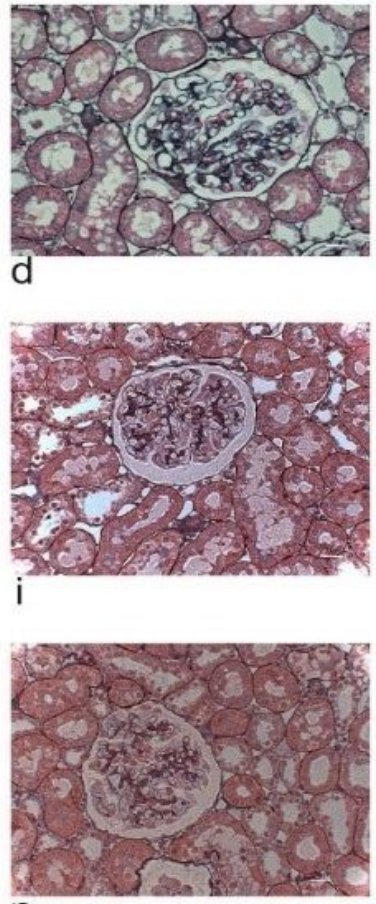

$\mathrm{n}$
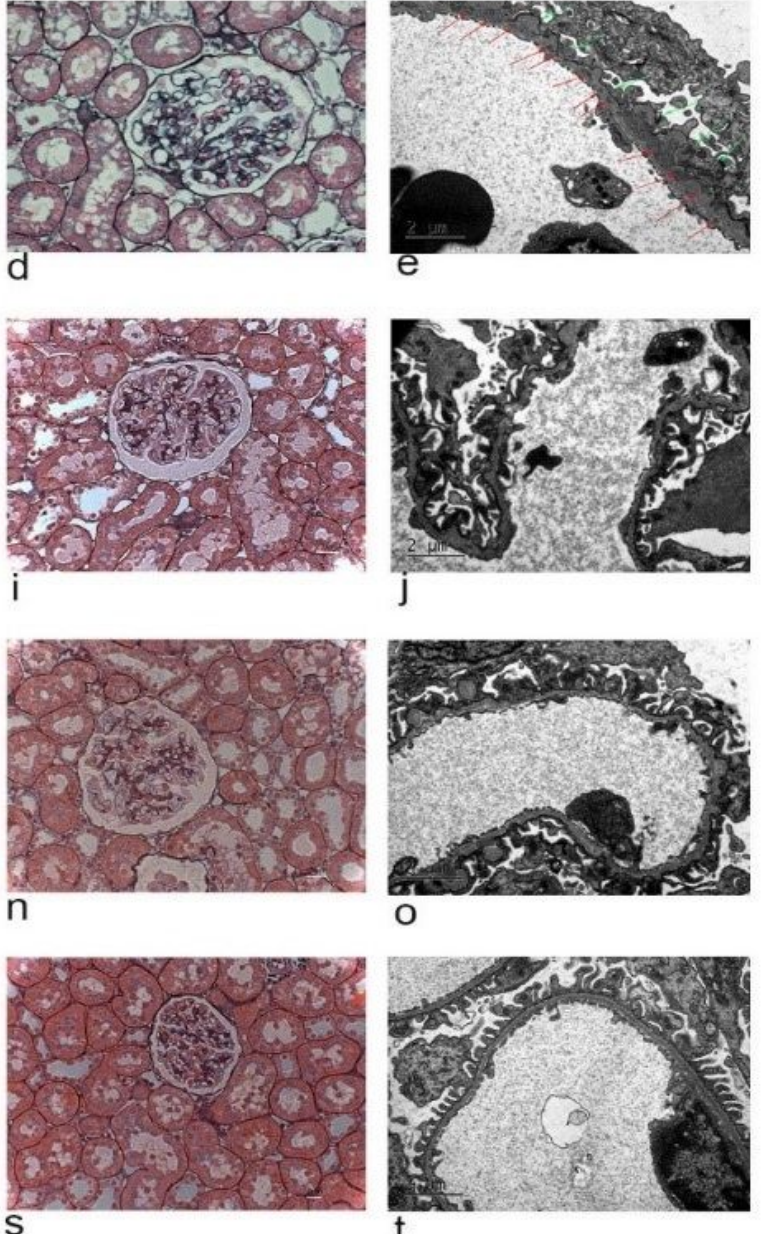

Figure 2

The kidney pathologic injuries of rats with passive Heymann nephritis and those after hESC-IMRC treatments.

The kidneys of rats with passive Heymann nephritis showed diffusive granular staining of IgG (a) and C3 (b) along the glomerular capillary walls (400x), glomerular basement membrane thickening (c) and scattered spike formation (d) on light microscopy (400x), and electron-dense deposits in the subepithelial area (red asterisks) and the podocyte foot processes diffusive fusion (green asterisks) on electron microscopy (e, 10000x). After hESC-IMRC treatments, the deposits of IgG $(\mathrm{f}, \mathrm{k})$ and C3 $(\mathrm{g}, \mathrm{l})$, the thickening $(h, m)$ and spikes $(i, n)$ of basement membrane, the electron-dense deposits and the podocyte foot processes fusion $(j, 0)$ were alleviated, in both the high-dose IMRC group $\left(6 \times 10^{6}\right.$ cells $)$ and the low-dose IMRC group $\left(3 \times 10^{6}\right.$ cells). No obvious kidney injury was observed in negative controls $(p-t)$. 
a.

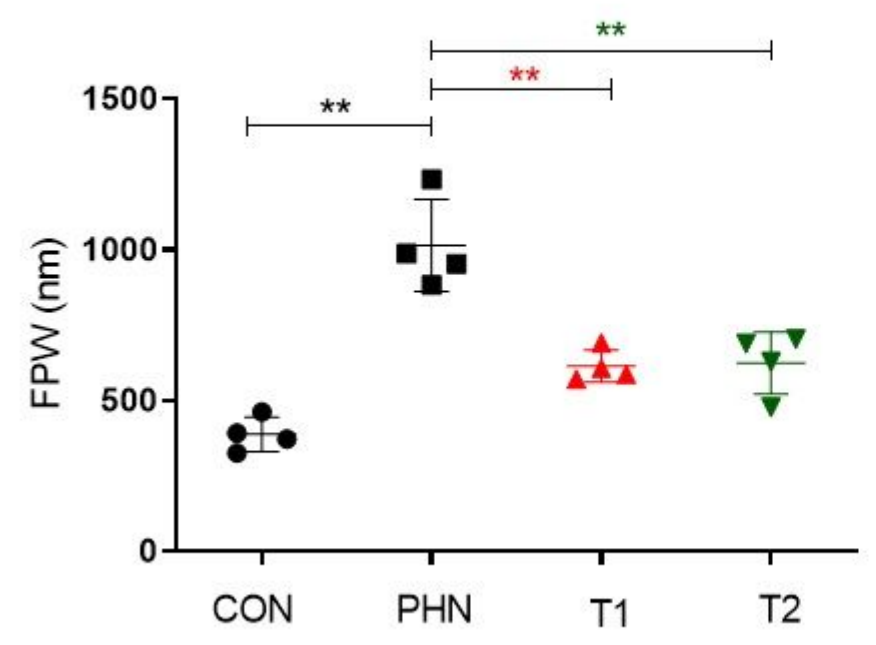

b.

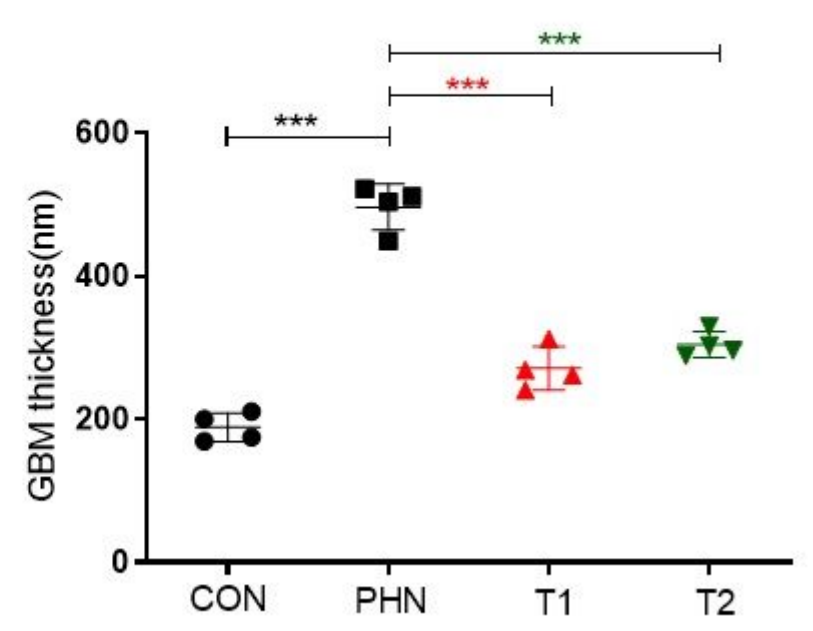

Figure 3

Quantitative analysis of podocyte foot process width (FPW) and glomerular basement membrane thickness.

The foot process width (a) in low-dose IMRC group $\left(3 \times 10^{6}\right.$ cells, $\left.T 1, n=4\right)$ and that in high-dose IMRC group $\left(6 \times 10^{6}\right.$ cells, $\left.T 2, n=4\right)$ was significantly decreased at week 7 , and was comparable to that in negative controls $(n=4)$. The thickness of glomerular basement membrane $(b)$ in high-dose IMRC group and low-dose IMRC group was significantly decreased at week 7 , and was comparable to that in negative controls. ${ }^{*} \mathrm{P}<0.05,{ }^{*} \mathrm{P}<0.01,{ }^{* \star *} \mathrm{P}<0.001$.

a.

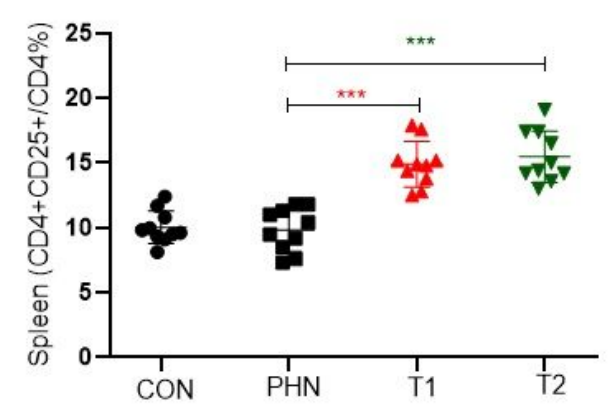

b.

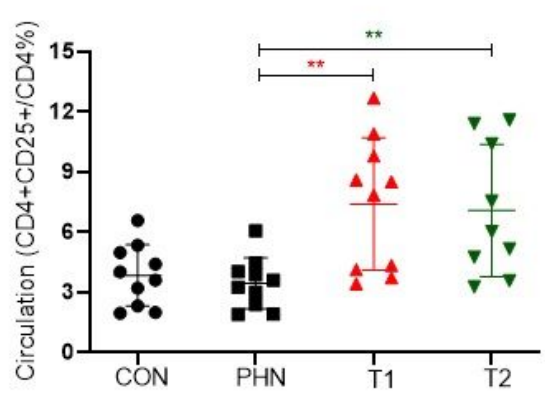

c.

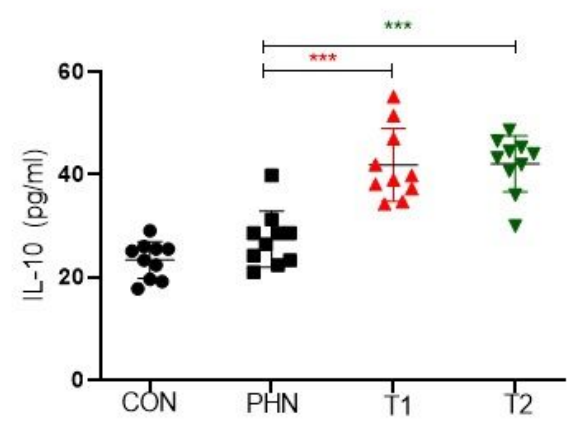

Figure 4

The proportion of $\mathrm{CD} 4^{+} \mathrm{CD} 25^{+} \mathrm{T}$ cells in circulation and in spleen. The proportion of $\mathrm{CD} 4^{+} \mathrm{CD} 25^{+} \mathrm{T}$ cells in $\mathrm{CD} 4^{+} \mathrm{T}$ lymphocyte cells was higher in circulation of the two IMRC treated rat groups (a). It was also 
higher in spleen of the two IMRC treated rat groups (b). The plasma level of IL-10 was increased in both groups of lower-dose (T1) and high-dose (T2) IMRC treatments (c). ${ }^{\star} P<0.05,{ }^{\star *} P<0.01,{ }^{\star \star \star *} P<0.001$.

The proportion of $\mathrm{CD} 4^{+} \mathrm{CD} 25^{+} \mathrm{T}$ cells in $\mathrm{CD} 4^{+} \mathrm{T}$ lymphocyte cells was higher in circulation of the two IMRC treated rat groups (a). It was also higher in spleen of the two IMRC treated rat groups (b). The plasma level of IL-10 was increased in both groups of lower-dose (T1) and high-dose (T2) IMRC treatments (c). ${ }^{*} \mathrm{P}<0.05,{ }^{* *} \mathrm{P}<0.01,{ }^{*} * * \mathrm{P}<0.001$.

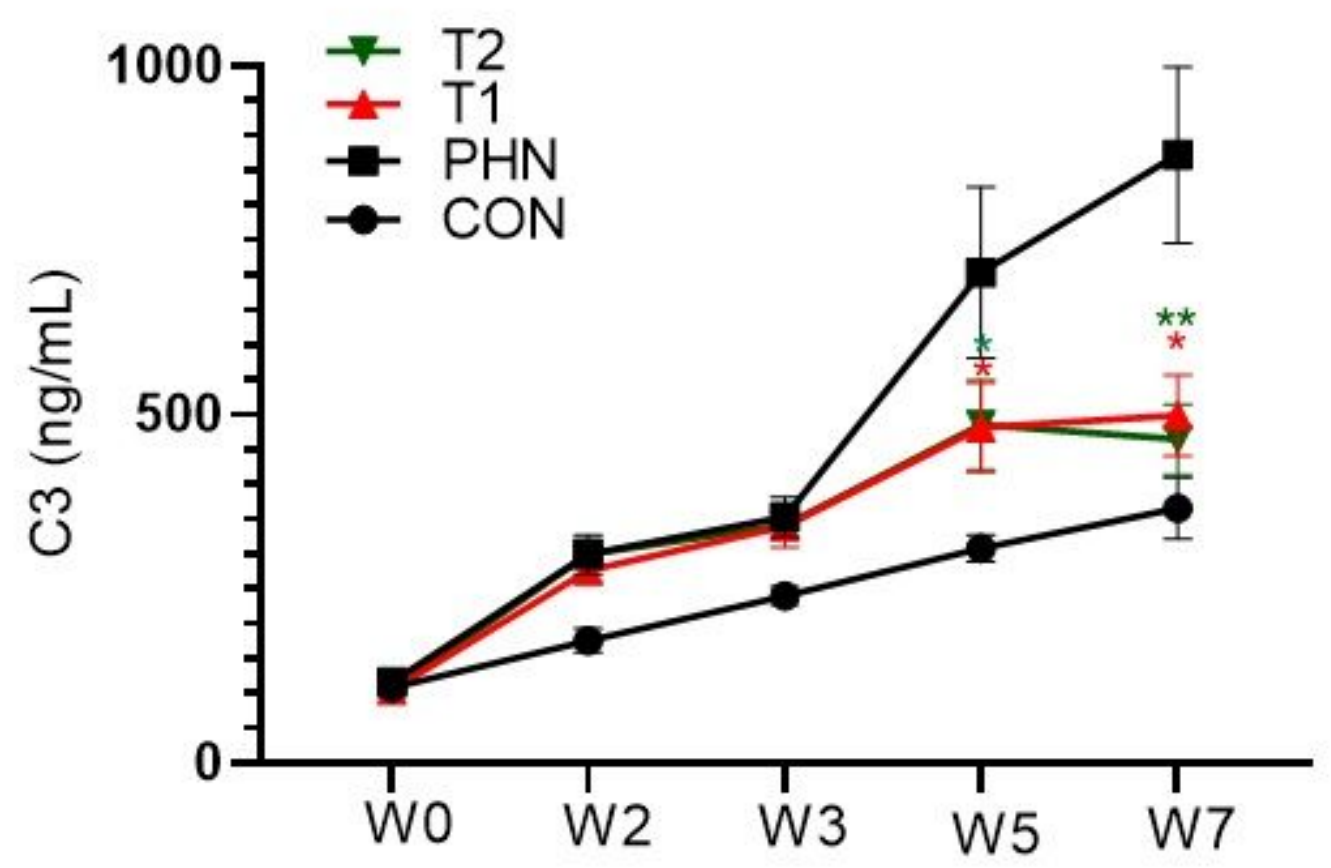

Figure 5

The plasma level of C3 in Heymann nephritis rats and those after hESC-IMRC treatments. The plasma level of C3 was increased from week 2 after the passive immunization of anti-rat Fx1A serum. After hESCIMRC treatment, it was significantly reduced in both groups of high-dose $(T 2, n=10)$ and low-dose $(T 1$, $n=10)$ compared to disease controls $(*)$, and was similar like that in negative controls $(C O N, n=10)$ at week 7. ${ }^{*} P<0.05,{ }^{*} P<00.01, * \star * P<0.001$.

The plasma level of C3 was increased from week 2 after the passive immunization of anti-rat Fx1A serum. After hESC-IMRC treatment, it was significantly reduced in both groups of high-dose $(T 2, n=10)$ and low-dose $(T 1, n=10)$ compared to disease controls $\left(^{*}\right)$, and was similar like that in negative controls (CON, $n=10)$ at week 7. ${ }^{*} P<0.05,{ }^{*} P<0.01, * \star * P<0.001$. 
a.

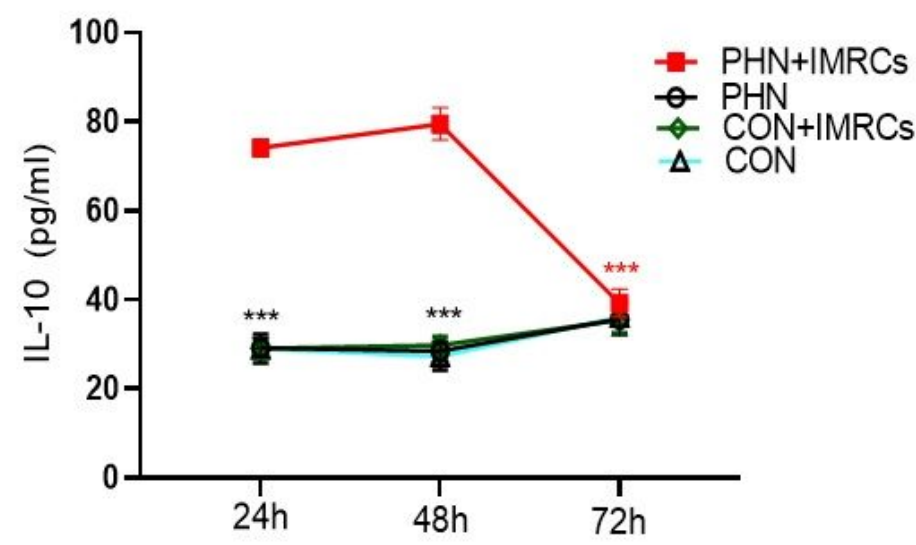

b.

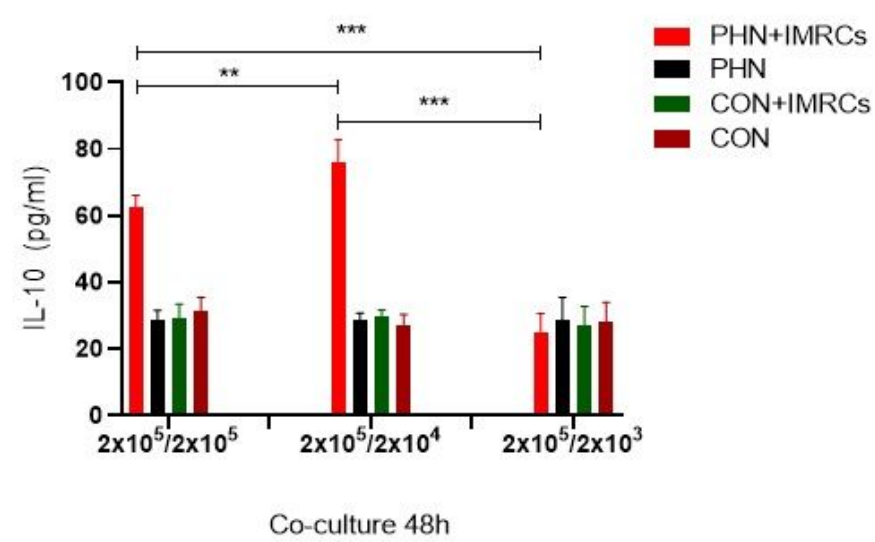

Figure 6

IL-10 production in the supernatant of splenic lymphocytes cocultured with hESC-IMRCs or not.

IL-10 was increased after $24 \mathrm{~h}, 48 \mathrm{~h}$, and $72 \mathrm{~h}$ of co-culture of splenic lymphocytes from disease rats with hECS-MSCs at a density ratio of 10:1 (a). IL-10 was higher in the co-culture supernatant with the ratio of splenocytes to IMRCs as 10:1, than that in the co-culture of splenocytes to IMRCs ratios as 1:1 and 100:1. ${ }^{*} \mathrm{P}<0.05, * \star \mathrm{P}<0.01, * \star * \mathrm{P}<0.001$. 